\title{
ADOECIMENTO MENTAL NO TRABALHO: UMA REALIDADE DOS DIAS ATUAIS
}

\author{
Mental adequacy at work: a reality of current days
}

L'adéquation mentale au travail: une réalité des jours actuels

Adecuación mental en el trabajo: una realidad de días actuales

\begin{abstract}
Elisana Ligia Garcia Barboza ${ }^{1}$
ORCID: https://orcid.org/0000-0001-5600-8894

Universidade Federal do Tocantins, Palmas, Tocantins, Brasil.

Psicóloga, Especialista em Psicopedagoia Clínica (PUC-RJ1995), Especialista em Gestão de Saúde(UNITINS/IHAC'S-2001), Especialista em Políticas Públicas de RH em Saúde(OPAS/ENSP/FIOCRUZ -2007), Mestre em Ciências da saúde (UFT-2017). Psicóloga Assistencial do HGP, Psicóloga UFT/SIASS
\end{abstract}

Erica Lissandra Bertolossi Dantas ${ }^{2}$

ORCID: http://orcid.org/0000-0001-7612-3611

Universidade Federal do Tocantins, Palmas, Tocantins, Brasil. Administradora junto a Universidade Federal do Tocantins (UFT). Possui graduação em Administração de Empresas pela Fundação Universidade Federal do Tocantins (2004), especialista em Políticas Públicas, MBA em Gestão de Pessoas e Mestra em Gestão de Políticas Públicas. Diretora de Desenvolvimento Humano no período de 2012 a 2015 e Pró-Reitora de Gestão e Desenvolvimento de Pessoas da UFT, área responsável pela Gestão de Pessoas da UFT de 2015 a 2017, período foi membro fundadora e participante da construção do Forgepe / Andifes (Fórum de Pró-Reitores de Gestão de Pessoas da Universidades Federais) e atual na Coordenação Nacional deste fórum até 2017..

\section{Marta Azevedo Santos ${ }^{3}$ \\ ORCID: https://orcid.org/0000-0002-3219-8555}

Universidade Federal do Tocantins, Palmas, Tocantins, Brasil.

Possui graduação em Psicologia pela Universidade Federal de Santa Catarina-SC (1990), Mestrado em

Educação pela Universidade Federal de Santa Catarina-SC (1997) e Doutorado em Psicologia pela

Universidade de Sevilla-ES (2003). Professora Associada, do quadro de professores da Universidade Federal do Tocantins, nos cursos de Enfermagem e Nutrição e do quadro permanente do Mestrado em Ciências da

Saúde. Tem experiência na área da Psicologia, Educação, Educação e Promoção em Saúde. Avaliação de

Política Pública. Desenvolvendo pesquisas na área interdisciplinar, nas linhas de Gestão e Planejamento, Avaliação de Políticas Públicas, Educação e Promoção da Saúde e Saúde do trabalhador. Consultora Técnica

1 elisana.palmas@uft.edu.br

2 ericalissandra@uft.edu.br

3 marta@uft.edu.br

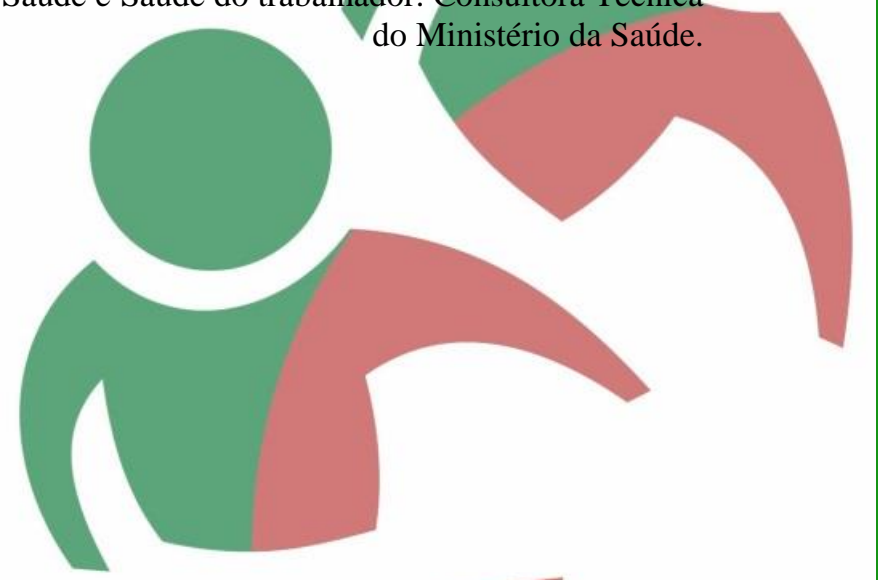




\title{
Resumo
}

Levantamento de dados de servidores de uma Universidade Federal do Norte do Brasil, com dados secundários obtidos no período de 2011 a 2018 que se afastaram para tratamento da saúde por transtornos mentais, ocasionados por questões que envolvem o trabalho, e/ou ambiente de trabalho, relações interpessoais no trabalho, relações hierárquicas. Hoje, as condições de ambiente, saúde e segurança no trabalho passam a ser compreendidas como garantias essenciais para a qualidade de vida dos indivíduos e direito à cidadania. Houve significativo aumento do número de afastamento de servidores por saúde mental. O presente artigo busca sinalizar alguns fatores que possam levar ao aumento destes índices nas IES.

Palavras-Chave: Saúde do Trabalhador. Absenteísmo. Saúde Mental.

\begin{abstract}
Data collection from workers of a Federal University of Northern Brazil, with secondary data obtained from 2011 to 2018. These workers were on leave for health treatment due to mental disorders caused by problems involving work or work environment, interpersonal relationships in the workplace, hierarchical relationships. Today, environmental conditions, health and safety at work are understood as essential guarantees for the quality of life of individuals and the right to citizenship. There has been a significant increase in sick leave due to mental health. The present article seeks to signal some factors that may lead to the rise of these indices in the HEI.
\end{abstract}

Keywords: Occupational Health. Absenteeism. Mental health.

\section{Resumé}

Collecte de données auprès des travailleurs d'une université fédérale du nord du Brésil, avec des données secondaires obtenues de 2011 à 2018. Ces travailleurs étaient en congé pour traitement médical en raison de troubles mentaux causés par des problèmes liés au travail ou à l'environnement de travail, les relations interpersonnelles sur le lieu de travail, les relations hiérarchiques. Aujourd'hui, les conditions environnementales, la santé et la sécurité au travail sont comprises comme des garanties essentielles pour la qualité de vie des individus et le droit à la citoyenneté. Il y a eu une augmentation significative des congés de maladie en raison de la santé mentale. Le présent article cherche à signaler certains facteurs qui peuvent conduire à la hausse de ces indices dans l'EES.

Mots-clés: santé au travail. L'absentéisme. Santé mentale

\section{Resume}

Recopilación de datos de servidores de una Universidad Federal del Norte de Brasil, con datos secundarios obtenidos de 2011 a 2018 que partieron para el tratamiento de la salud por trastornos mentales, causados por problemas relacionados con el trabajo y / o el entorno laboral. trabajo, relaciones interpersonales en el trabajo, relaciones jerárquicas. Hoy, las condiciones ambientales, la salud y la seguridad en el trabajo se consideran garantías esenciales para la calidad de vida de las personas y el derecho a la ciudadanía. Hubo un aumento significativo en el número de bajas por enfermedad debido a la salud mental. El presente artículo busca señalar algunos factores que pueden conducir al aumento de estos índices en la IES.

Palabras clave: Salud ocupacional. Absentismo. Salud mental.

\section{INTRODUÇÃO}

O presente artigo é fruto de uma inquietação que envolveu os profissionais que

trabalham em um setor Subsistema Integrado de Atenção à Saúde do Servidor (SIASS) no 
Estado do Tocantins. Este setor é responsável por coordenar e integrar ações e programas nas áreas de assistência à saúde, perícia oficial, promoção, prevenção e acompanhamento da saúde dos servidores de diversas instituições federais. Neste artigo, nos deteremos no levantamento dos dados de servidores que se afastarem por transtornos ligados à saúde mental no período compreendido entre 2011 e 2018. Para compreender a questão do aumento do número de afastamentos de servidores do trabalho tomou-se como base o referencial teórico sobre a conceituação do que é trabalho, saúde do trabalhador, saúde mental, absenteísmo, já que é relevante compreender quais fatores estão levando os trabalhadores a se afastarem por motivo de saúde mental.

A partir da metade do século XX, com o avanço da sociedade capitalista, observa-se uma pressão constante do capital contra a grande massa de trabalhadores existente em quase todo o mundo (DIAS, 1994). Refletindo no desempenho do trabalhador na realização de sua força de trabalho e na execução de seu labor na prática cotidiana, possibilitando a perda da manutenção do seu "status quo" e da sobrevivência. Entretanto, essa pressão poderá levar o trabalhador ao adoecimento e consequentemente à perda momentânea ou permanente, de sua capacidade para o trabalho.

Dessa forma, desenvolvem doenças relacionadas ao trabalho, tais como: transtorno de ansiedade, síndrome do pânico, entre outras. Podendo inclusive, acarretar o desenvolvimento de doenças de cunho psicológico mais grave, a chamada doença mental.

Doença mental, de acordo com Codo (2002), significa um conflito do indivíduo consigo mesmo, ou do indivíduo com seu outro eu; podemos assim dizer que saúde mental é um bem-estar do indivíduo com seu próprio eu e com o mundo em que convive. Ainda de acordo com este autor, existem algumas variáveis já reconhecidas como importantes para determinar o nível de saúde mental do trabalhador, como o controle do trabalhador sobre o trabalho, a rotina, a importância social do trabalho, a relação com os colegas de trabalho e a hierarquia e os conflitos trabalho-família.

É preciso destacar que o sofrimento psíquico e a doença mental ocorrem quando, e apenas quando, afeta esferas de nossa vida que são significativas, geradoras e transformadoras de conhecimento (CODO, 2002).

Entende-se por doença, a perda de várias condições de vida e de cidadania, tais como descrito nas cartas de promoção de saúde, “A promoção e proteção da saúde da população é indispensável para o desenvolvimento econômico e social sustentado e contribui para melhorar a qualidade de vida e alcançar a paz mundial" (MINISTÉRIO DA SAÚDE, 2002). 
Desta forma, a saúde é determinada pelas várias condições do meio ambiente, pelas próprias condições de vida dos indivíduos e pelo equilíbrio entre fatores externos e internos do ser humano. Concluímos, que o equilíbrio ideal está no equilíbrio global de todos os setores da vida de cada indivíduo, que incluem condições de moradia, acesso à educação e ao controle social, emprego e renda entre outros. Os sujeitos que perdem este equilíbrio são acometidos pelas doenças psicossomáticas, psicológicas e mentais.

Observando o conceito de trabalho a partir do final do séc. XX, é concebido como uma atividade que envolve o homem em todas as suas dimensões, exercendo importante papel na construção da subjetividade humana, e como tal, um elemento constitutivo da saúde mental e coletiva. Conforme Bridges (1995), o trabalho, além de contribuir fortemente para a sobrevivência material dos indivíduos, organiza e estrutura a vida das pessoas dando-lhes uma identidade, proporcionando uma rede de relações e de contatos, estruturando seu tempo e construindo espaço na sociedade através de direitos e obrigações.

Dada a importância do trabalho na vida humana, também pode ocorrer um processo de desestruturação nesta relação de trabalho. Dependendo do significado que o trabalhador estabelece com o seu fazer, e relacionando-o com as condições da materialidade para realização do seu trabalho, podem ocorrer um forte conflito entre estes processos, ocasionando o chamado adoecimento mental.

Uma das consequências evidentes, relacionadas ao adoecimento do trabalhador, é o destacado aumento do absenteísmo.

O absenteísmo é um fator que merece atenção para melhoria nos processos de trabalho. Ferreira (1986), define o absenteísmo como sendo a ausência habitual ao emprego, ou seja, é a ausência do trabalhador das suas atividades laborais cotidianas. Bulhões (1998) acrescenta ainda que o absenteísmo compreende todas as causas de ausência do trabalhador ao seu local de trabalho, tais como: doença de longa duração, acidentes, licença a saúde, licença maternidade, afastamento por problemas familiares ou formalidades judiciais, cursos fora e dentro da empresa. Importante frisar que situações como greve, repouso semanal ou compensado, férias e feriados, não são considerados absenteísmo.

Uma outra questão que precisamos abordar é como está hoje o campo da Saúde do Trabalhador. Segundo Minayo-Gomez (2011), o campo da saúde do trabalhador tem sua origem num cenário de luta pela redemocratização do Brasil, a partir da década de 1980, sendo esta, uma discussão relativamente nova. 
As discussões do campo da saúde do trabalhador, ocupa vários espaços e lugares sociais diferentes, e envolve diversos atores, que levam ao questionamento das concepções das políticas públicas de saúde vigentes, e traz diversos fatores para sua constituição enquanto campo.

Daí formular uma política de saúde do trabalhador significa, portanto, contemplar uma gama ampla de fatores de condição da saúde e da doença. Especificamente para o setor público de saúde, do âmbito municipal, estadual e federal, é premente a necessidade de consolidar ações de saúde do trabalhador que abranjam da vigilância à assistência em seu sentido amplo.

Acompanhando o processo de democratização do País, uma série de práticas no âmbito da Saúde Pública levou a novas perspectivas nas relações de trabalho e saúde. Alguns estudos recuperam parte desse percurso (Dias, 1994; Lacaz, 1994 apud MinayoGomez, 2011), sistematizam experiências inovadoras (Costa et al., 1989; Pimenta \& Capistrano, 1988 apud Minayo-Gomez, 2011) ou apontam as diferenças conceituais e teórico metodológicas que distinguem da Medicina do trabalho e da Saúde Ocupacional (Tambellini, 1986; Mendes \& Dias, 1991 apud Minayo-Gomez, 2011).

A identidade do campo de saúde do trabalhador a princípio tem como referência a Saúde ocupacional, fundamentada por práticas e conhecimentos da clínica, da medicina e da engenharia de segurança. No entanto, saúde do trabalhador, agrega além, dessas áreas, outras áreas que ampliam a visão.

Saúde do trabalhador é um campo da saúde coletiva, e como tal, está composta pelo tripé, epidemiologia, administração e planejamento em saúde e ciências sociais em saúde, que abrangem outras disciplinas auxiliares.

Assim, o campo saúde do trabalhador supera a visão da saúde ocupacional e situa-se na perspectiva da saúde como direito, essa perspectiva, transcende o marco do direito previdenciário-trabalhista. Mendes \& Dias (1991), coloca que o objeto da saúde do trabalhador é o processo de saúde e doença dos grupos humanos em sua relação com o mundo do trabalho.

Araújo (2012) afirma que: O aumento dos afastamentos para tratamento de saúde entre os servidores públicos docentes, no Brasil, tem sido significativo nas últimas décadas. No entanto, poucos são os estudos realizados no Brasil sobre este fenômeno, sendo que a produção científica relacionada a esta classe trabalhadora está restrita a algumas categorias mais específicas, como trabalhadores da saúde, por exemplo. 
Pensando nestes fatores que envolvem o trabalhador, saúde mental, absenteísmo e saúde do Trabalhador, analisaremos a evolução dos afastamentos de servidores de uma IES (Instituição de Ensino Superior) do norte do País, nos quais observamos o aumento dos afastamentos por saúde mental num período de sete anos, elevando-se os índices de absenteísmo por trabalho-doença.

\section{METODOLOGIA}

Trata-se de uma pesquisa de caráter descritivo e exploratório a fim de identificar os afastamentos de servidores de uma Instituição de Ensino Superior por motivo de saúde mental, ou seja, afastamentos classificados por Código Internacional de Doenças (CID - F), que é o CID ao longo de oito anos, doenças de transtornos mentais (Estresse, Depressão, Ansiedade e outras), relacionadas ao trabalho. $\mathrm{O}$ estudo foi realizado por meio de pesquisa ao banco de dados do SIASS (Subsistema Integrado de Atenção do Servidor da Saúde) no período março de 2011 a março de 2018.

Foram realizadas consultas ao banco de dados do SIAPE, módulo saúde, no período de março a junho de 2019, onde levantamos os dados relativos a uma Instituição de Ensino Superior, fizemos este recorte, por observarmos ser relevante o número significativo de afastamentos de servidores (docentes) desta Instituição, uma vez que, o SIASS atende 28 instituições no Estado do Tocantins.

Utilizamos a pesquisa exploratória, que visa a descoberta, a elucidação de fenômenos ou a explicação daqueles que não eram aceitos apesar de evidentes. (Gonçalves, 2014).

Neste estudo, utilizamos os dados quanto ao número de afastamentos por gênero, dias de afastamento e faixa etária dos servidores afastados por CID-F e a relação com o afastamento do trabalho.

\section{RESULTADOS E DISCUSSÃO}

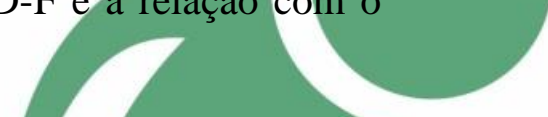

Em análise dos dados, dos últimos sete anos, observou-se que a instituição federal de ensino superior, contou 1.359 afastamentos por vários motivos de saúde, com ausência de servidores totalizando 6566 dias em virtude de problemas de saúde diversos. Foi verificado neste período afastamento de 188 docentes, sendo que, $14 \%$ deste total, ocorreram em 
virtude de atestado por motivo de saúde mental. Assim, através da escuta psicológica realizada com os servidores durante perícia, percebemos que a maioria dos casos remetiam as relações de trabalho (conflito nos vínculos hierárquicos e com os pares, ambiência e organização do trabalho). Comparado ao número de outros tipos de afastamentos, 188 pessoas em sete anos, pode não ser um dado alarmante, porém, quando analisado os dias de afastamentos por saúde mental, observou-se que estes correspondem a aproximadamente 2.402 dias, portanto $37 \%$ dos dias de ausências ao trabalho em virtude de transtornos mentais.

É notório que os problemas de saúde mental no serviço público têm se tornado um grave problema no decorrer dos anos. Investigando os dados, ano a ano, verifica-se um gráfico ascendente em comparação do primeiro ano pesquisado ao último. Observamos um crescimento de aproximadamente $2.800 \%$ (dois mil e oitocentos por cento) no número de afastamento por problemas de saúde mental nesta instituição de ensino.

Este problema é agravado muitas vezes pelas relações de trabalho, ambiência e relações hierárquicas inadequadas, o que leva o servidor ao adoecimento. A cultura gerencialista está cada vez mais voltada para as tarefas e menos para as pessoas, precarizando o trabalho, desmotivando o servidor, e fazendo com que as tarefas laborais pressionem cada vez mais o indivíduo, dificultando os espaços de diálogo e de exercício da criatividade. Percebemos que muitas vezes, a chefia não ouve e não avalia o perfil e o desejo do servidor quanto o local de melhor adequação. E, este olhar da chefia atendendo ao perfil do servidor ajuda a melhorar o desempenho do mesmo, ainda que as condições não sejam favoráveis.

Dejours (2012), fala do prazer e sofrimento no trabalho, contudo, o adoecimento é decorrente da impossibilidade da contínua transformação do sofrimento em prazer. Contudo, quando não há ressignificação do sofrimento, este pode vir a causar o adoecimento. Uma vez que este trabalhador perde e/ou não encontra formas adequadas de executar suas atividades/funções com certa autonomia e significado para si mesmo.

Assim vemos que o adoecimento mental no trabalho, está ligado diretamente com as relações e os sentimentos de prazer e realização que o trabalho traz ao indivíduo, quando o trabalho começa a perder o sentido por inúmeras razões a saúde mental fica abalada, e consequentemente a produtividade.

Conforme Bridges (1995), o trabalho, além de contribuir fortemente para a sobrevivência material dos indivíduos, organiza e estrutura a vida das pessoas dando-lhes 
uma identidade, proporcionando uma rede de relações e de contatos, estruturando seu tempo e construindo espaço na sociedade através de direitos e obrigações.

Dada a importância do trabalho na vida humana, também pode ocorrer um processo de desestruturação nesta relação de trabalho. Dependendo do significado que o trabalhador estabelece com o seu fazer, e relacionando-o com as condições da materialidade para realização do seu trabalho, podem ocorrer um forte conflito entre estes processos, ocasionando o chamado adoecimento mental.

Visando compreender melhor os dados, segmentou-se os dados por gênero, verificase que $62 \%$ dos afastamentos ocorreram no gênero feminino e $38 \%$ no gênero masculino. Sendo o gênero feminino prevalecente em todos os anos, salvo em 2013 e 2014 que o afastamento de docentes do gênero masculino foi ligeiramente maior que o feminino.

A participação das mulheres na força de trabalho brasileira vem aumentando de forma crescente (SENNA; FREITAS, 1993; e OLIVEIRA 1999a). As mulheres estão em diferentes profissões, particularmente nas exigem destreza manual e naquelas que são consideradas tipicamente femininos.

Ao pensar sobre a história da trajetória do trabalho, vemos que o capitalismo industrial, ocorrido com a Revolução Industrial em 1848, com a introdução das máquinas e o modelo taylorista, impulsionou e exigiu o crescimento da produção. Os operários nessa época eram regidos pela eficácia rígida do sistema produtivo. A migração campo-cidade e as necessidades de sobrevivência, fez com os trabalhadores se submetessem às condições impostas pelo capitalismo.

A necessidade de subsistência, acaba, por fazer o trabalhador se sujeitar às condições de trabalho oferecida, a fim de manter-se no emprego, assim, a relação saúde e trabalho nasce em condições bastante penosa, sem garantias e sem ações preventivas. $\mathrm{O}$ trabalho feminino, já nessa época era marcado por um valor mais baixo e pela duplajornada.

Dessa forma, nessa época não se falava em saúde do trabalhador. Ao se falar de adoecimento, estava se falando em demissão, desemprego. Se houvesse manifestação de queixa decorrente das condições de trabalho, o trabalhador era demitido, gerando assim, uma representação social da doença para os trabalhadores, alicerçada no medo da perda do emprego, vergonha, fraqueza e negatividade de toda essa situação.

Silva (1997) refere que a feminilização da força de trabalho não é exclusiva de um campo profissional, estando presente em várias profissões, notadamente nas áreas de educação e saúde. 
Gráfico 1: Afastamentos entre 2011 e 2018

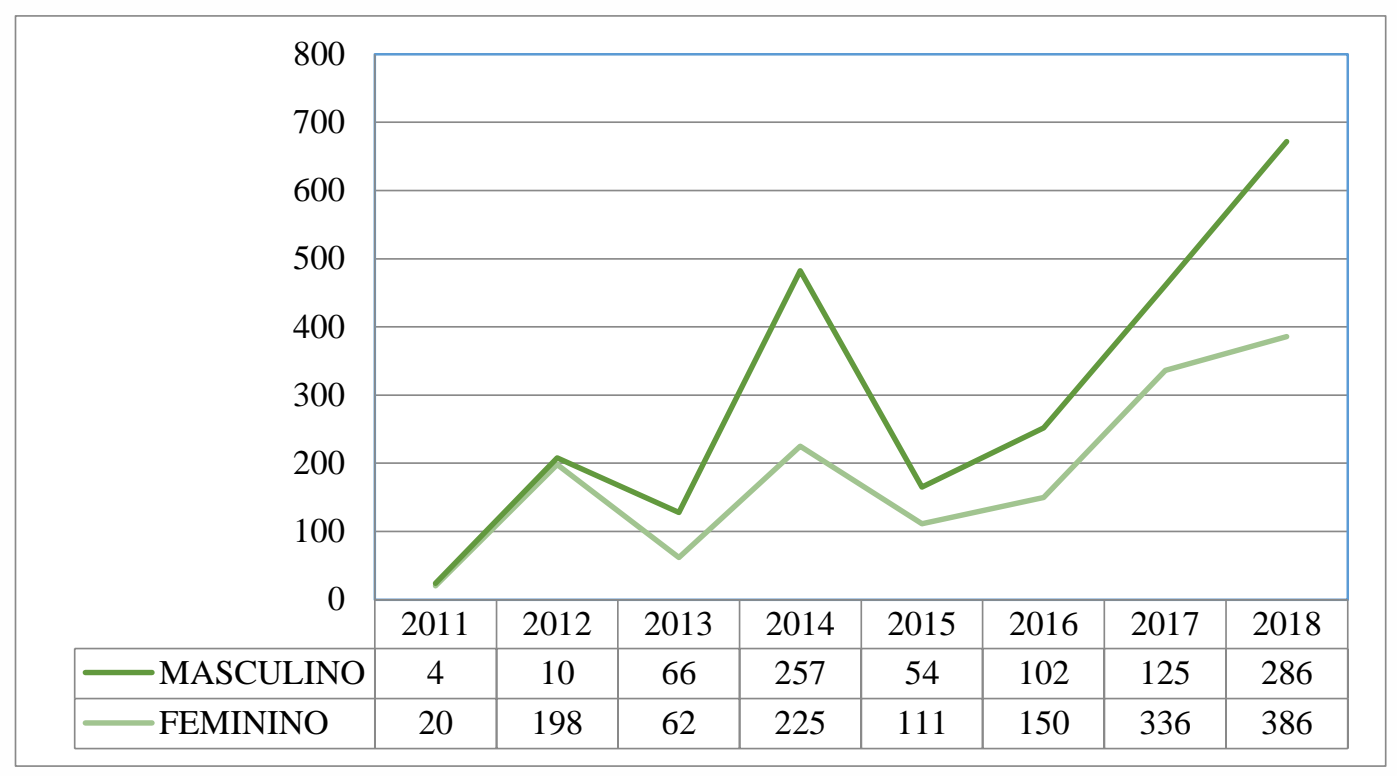

Fonte: Autoras

Assim podemos inferir, como se apresenta em diversos estudos, maior percentual de afastamento de mulheres em alguns setores, ocorre devido a prevalência do número maior de servidores do gênero feminino, e ora pelos vários papéis desempenhados pelas mulheres o que favorece maior quantitativo nos afastamentos.

Ainda em análise dos dados, considerando os contextos apresentados, estratificamos os dados por faixa etária, visando verificar qual seria faixa de idade que mais ocorriam os afastamentos. Detectamos pelos dados que $57 \%$ dos afastamentos ocorreram na faixa etária de 31 a 45 anos, ou seja, idade em que o docente está, ou deveria estar, em plena atividade intelectual.

Assim destaca-se a idade de 36 a 40 anos que está acima de $60 \%$ a mais que o segundo e terceiro lugar em afastamentos. Este fato pode ser preocupante futuramente caso permaneçam desta forma, uma vez que estes podem ocasionar outras doenças ou mesmo a inatividade. Neste sentido dias de afastamento por problemas de saúde não impactam apenas na vida do servidor afastado, mas também no ambiente de trabalho, que poderá gerar uma sobrecarga nos demais colegas ocasionando outros problemas funcionais ou de saúde.

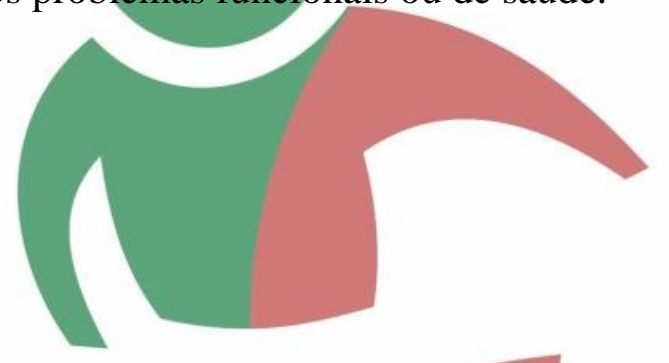




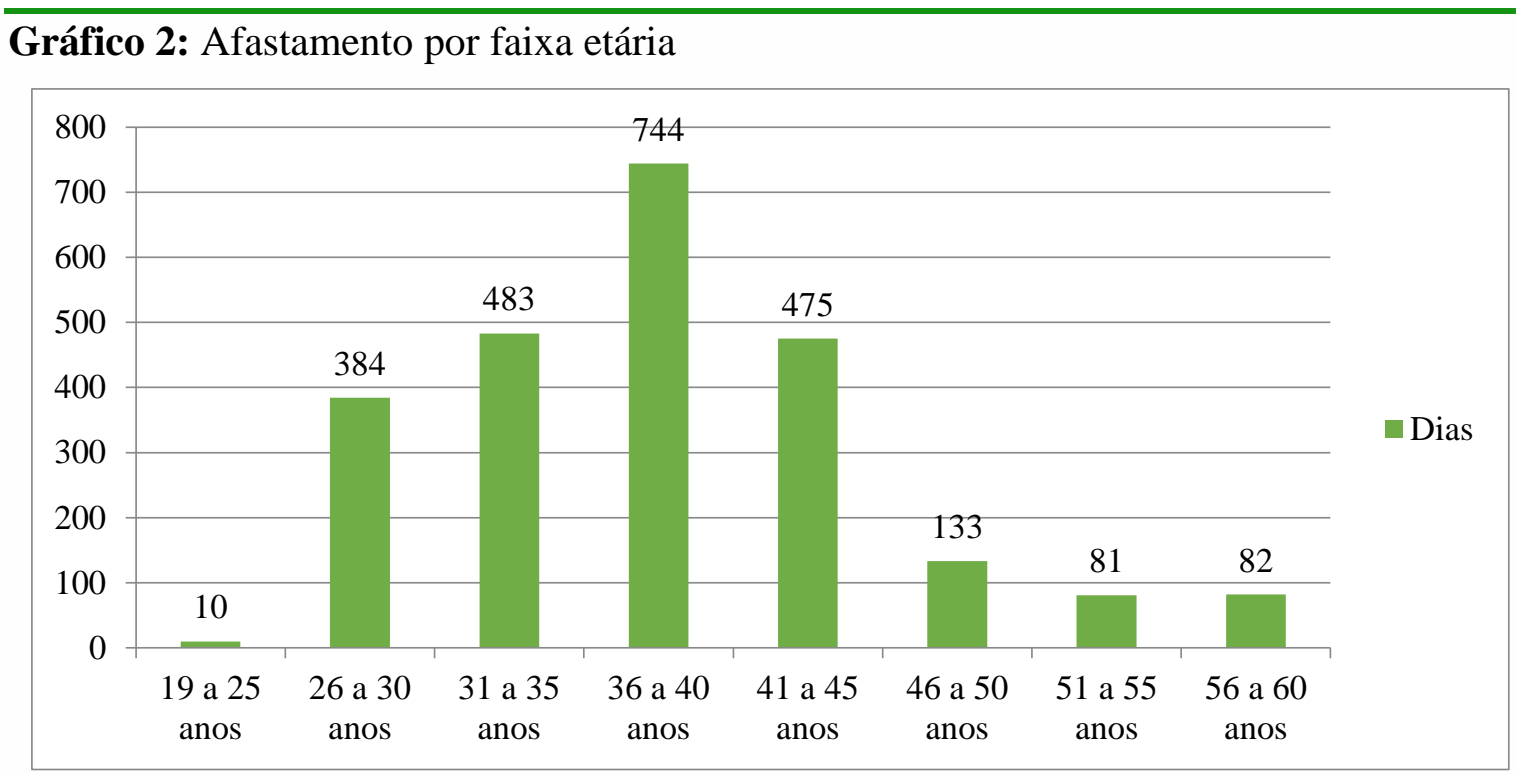

Fonte: Autoras

Estudos epidemiológicos bem conduzidos, permitem conhecer as diferentes variáveis que afetam o absenteísmo, como sexo, idade, estado civil, turnos de trabalho dias da semana, meses do ano, fatores psicológicos, causas médicas de faltas ao trabalho entre outros, assim como auxilia na prevenção do mesmo.

Fernandes e Marzialle (2014), colocam que tais fatores se tornam preocupantes, pelas características atuais, o estresse relacionado ao trabalho e suas consequências para a saúde dos trabalhadores. Diferentes correntes de pensamento no campo da saúde mental e trabalho versam sobre a questão, dentre as quais se destacam duas teorias: a do estresse - que investiga o estresse e o trabalho e recebe o nome de work stress - e a das ciências sociais, que privilegia as relações de poder. As causas do work stress são variadas e envolvem episódios de mobbing (forma de pressão psicológica ou moral), assédio psicológico, intimidação e outras formas de violência que estão cada vez mais presentes no ambiente de trabalho. Esse fenômeno provoca danos psicofísicos e sociais, gerando um efeito negativo sobre o trabalhador e a empresa. Assim, na tentativa de lidar com o estresse, os profissionais podem recorrer a comportamentos pouco saudáveis, a exemplo do abuso de álcool e outras drogas. Ademais, a crise econômica e a recessão também levaram a um aumento do estresse relacionado ao trabalho, da ansiedade, da depressão e de outros distúrbios mentais, inclusive conduzindo algumas pessoas ao extremo do suicídio. 
Penatti et al. (2006) concordam que o absenteísmo no Brasil não é muito pesquisado e acrescentam que o presenteísmo ainda é pouco conhecido por parte dos trabalhadores e das organizações. E não há muitos dados científicos sobre as faltas do docente, também pouco se sabe sobre o docente que está presente na escola e não produz como se esperava que ele produzisse.

Tavares et al. (2009) afirmam que, no Brasil, há ainda poucos estudos sobre absenteísmo de docentes. Assim, trabalhos científicos sobre absenteísmo por doença são muito escassos no meio educacional, o que evidencia e confirma a necessidade de pesquisas para fundamentar o planejamento e adequação dos recursos humanos neste setor.

\section{CONSIDERAÇÕES FINAIS}

Este estudo procurou fazer o levantamento dos afastamentos de servidores de Instituição de Ensino Superior, a fim de verificar o alto índice de afastamentos com questões de Saúde mental. Chamou-nos a atenção o fato do aumento do índice de afastamentos por essa questão, e nos faz pensar quais os fatores têm contribuído para que servidores (docentes) apresentem o adoecimento mental.

No entanto, estabelecer a relação entre adoecimento mental e trabalho não consiste em uma tarefa fácil, visto a complexidade do adoecimento psíquico, que envolve várias dimensões do sujeito e suas particularidades.

Em termos estatísticos, dados apontam que mais de 400 milhões de pessoas são afetadas por transtornos mentais ou comportamentais em todo o mundo. No Brasil, os transtornos mentais são a terceira causa de longos afastamentos do trabalho por doença. Por essa razão, os problemas de saúde mental já ocupam cinco posições no ranking das dez principais causas de incapacidade para o trabalho, representando um fenômeno mundial

Para entender o adoecer dentro do processo de trabalho, é necessário perceber quem é o trabalhador que adoece e de que forma ele está inserido no processo produtivo. No caso do professor, sua qualidade de vida revela-se seriamente comprometida diante de condições de trabalho adversas, como por exemplo: baixos salários, múltiplas tarefas que thes vêm sendo atribuídas, condições de trabalho que afetam sua autonomia na condição dos processos de ensino aprendizagem, entre outros fatores. Esta intensificação do trabalho desencadeadora da insatisfação no trabalho reduz a qualidade da educação. 
Os processos de desgaste físico e mental dos professores representam consequências negativas não somente para os professores, mas também para o aluno e para o sistema de ensino. Os custos sociais e econômicos podem ter múltiplos desfechos: absentismo, acidentes e enfermidades diversas, físicas, comportamentais e psíquicas. (LANDINI, 2006).

Assim, podemos inferir que quando um professor se abstém, se ausenta de seu trabalho por afastamento de saúde mental, os alunos passam a ter muitos e diferentes educadores. Partindo do princípio de que o professor para conseguir transmitir os conhecimentos de maneira com que os alunos se interessem e aprendam tenha que partir do cotidiano do aluno, e consequentemente conhecerem a realidade dos mesmos. Quando esta relação não é constituída, a qualidade de ensino diminui drasticamente. Trazendo consequência para formação deste aluno, levando-o a uma descontinuidade na forma de aplicação dos conteúdos e em última instância causando uma perda de interesse e/ou desestímulo neste aluno.

Em suma, nos chama a atenção as consequências, tais como, o tempo de afastamento por saúde mental, que geralmente é por período bastante longo resultando no aumento de dias perdidos no ano. Percebemos que, a faixa etária dos servidores que se afastaram por doença mental encontra-se no auge da vida produtiva, e este é um fator relevante, e que o percentual de pessoas do gênero feminino é bem maior que do gênero masculino.

Assim, este levantamento, abre caminho para outras pesquisas, com o aprofundamento das causas/fatores que estão levando estes servidores ao afastamento por adoecimento mental.

\section{REFERÊNCIAS}

Araújo, J. P. Afastamento do trabalho: absenteísmo e presenteísmo em uma Instituição Federal de Ensino Superior. 2012. 122 f. Dissertação (Mestrado em Ciências da Saúde) - Universidade de Brasília, Brasília, 2012.

BRASIL, Ministério da Saúde. Secretaria de Políticas de Saúde. Projeto Promoção da Saúde. As Cartas da Promoção da Saúde / Ministério da Saúde, Secretaria de Políticas de Saúde, Projeto Promoção da Saúde. - Brasília: Ministério da Saúde, 2002. http://bvsms.saude.gov.br/bvs/publicacoes/cartas_promocao.pdf.

Bridges, W. Mudanças nas relações de trabalho. São Paulo. Makron Books, 1995.

Bulhões, I. Riscos do trabalho de enfermagem. 2. ed. Rio de Janeiro: Folha Carioca; 1998. 
Codo, W. (Org.), Saúde mental \& Trabalho: Leituras. Petrópolis: Vozes, 2002.

Dejours, C. Trabalho, trabalho e emancipação. Brasília: Paralelo 15, 2012.

Dias, E. C. Pontos para uma reflexão sobre a atenção à saúde dos trabalhadores no Sistema de Saúde no Brasil. Belo Horizonte, 1994.

Fernandes, M.A.; Marziale, M.H.P. Occupational risks and illness among mental health workers. Acta Paul Enfermagem. 2014; 27(6): 539-47. http://dx.doi.org/10.1590/1982$\underline{0194201400088 .}$

Ferreira, A. B. de H. Novo dicionário da língua portuguesa, Rio de Janeiro, 1986.

Landini, S. R. Professor, Trabalho e Saúde: as políticas educacionais, a materialidade histórica e as consequências para a saúde do trabalhador - professor. São Carlos, 2006.

Mendes, R.; Dias, E. C. Da medicina do trabalho à saúde do trabalhador. Rev. Saúde Pública. São Paulo, n.25, 1991.

Minayo-Gomez, C. (Org.). Saúde do trabalhador na Sociedade Brasileira Contemporânea. Rio de Janeiro. Fiocruz, 2011.

Nogueira, D. P.; Azevedo, C. A. B. Absenteísmo - doença em mulheres. Rev. Bras. Saúde Ocup.,v. 38, n. 10, p. 48-51, 1982.

Penatti, I.; Zago, J. S.; Quelhas, O. Absenteísmo: as consequências na gestão de pessoas. II

Pimenta, A. L. \& Capistrano Filho, D., 1988. Saúde do Trabalhador. São Paulo: Hucitec.

Santos, R. C. V., Léda D. B., Pinto e Silva E, Freitas L.G. Trabalho intensificado de professores da educação básica e superior: confluências e especificidades. Trabalho (En)Cena. 2016;1(1):50-68.

Senna, D. M; Freitas, C. U. A Mulher em Particular. In: Rocha, L. E; Rigotto, R; Buschinelli, J. T. (Orgs.). Isto é trabalho gente? Vida, Doença e Trabalho no Brasil. São PauloVozes, 1993.

Tambellini, A. T. Avanços na formulação de uma política de saúde do trabalhador. In: I Conferência Nacional de Saúde do Trabalhador. Rio de Janeiro: Escola Nacional de Saúde Pública, Fundação Oswaldo Cruz. 1986. (mimeo).

Tavares, P. A.; Camelo, R.; Kasmirski, P. “A falta faz falta? Um estudo sobre o absenteísmo dos professores da rede estadual paulista de ensino e seus efeitos sobre o desempenho escolar" In: Área ANPEC: Área 11- Economia Social e Demografia, 2009. 